\title{
ORIGINAL ARTICLE \\ Prospective study of barriers to discharge from a spinal cord injury rehabilitation unit
}

\author{
PW New ${ }^{1,2}$
}

Study design: Prospective open cohort case series of consecutive patients admitted with spinal cord damage to a spinal rehabilitation unit (SRU) between 1 January 2008 and 31 July 2013.

Objectives: Measure the prevalence of barriers to discharge, their reasons and resulting additional unnecessary days in hospital.

Setting: SRU, Victoria, Australia.

Methods: Consecutive SRU admissions had prospective documentation of key clinical and demographic characteristics, the occurrence of any discharge barrier, the cause(s) and duration of unnecessary hospitalisation.

Results: There were 235 patients in the study; 138 (58.7\%) were male and the median age was 63 years. Eighty-six (36.6\%) patients had a discharge barrier. The most common reasons for a discharge barrier were: waiting for approval for long-term and supported care or services, residential care, home modifications, family deliberations regarding discharge planning and the provision of equipment necessary for discharge. The reasons accounting for the greatest number of additional hospital days were: home modifications, residential care, equipment necessary for discharge, waiting for approval for long-term and supported care or services and accommodation for people unable to return to their previous residence without readily available alternatives. Over the study period $17.5 \%$ (3176/18 184) of all bed-days were occupied by patients deemed to be clinically ready for discharge from the SRU but who had a discharge barrier.

Conclusions: Barriers to discharge from rehabilitation for patients with spinal cord damage are common, substantial, and represent an important opportunity for health systems improvement.

Spinal Cord (2015) 53, 358-362; doi:10.1038/sc.2014.166; published online 30 September 2014

\section{INTRODUCTION}

Problems with patient-flow in hospital systems have been well described in emergency departments ${ }^{1-3}$ and acute care hospitals, ${ }^{4-6}$ and the challenge of managing the increase in demand for hospital services is recognised as a major issue worldwide. It is anticipated that as a result of fiscal constraints in health-care funding and population ageing $^{7}$ resulting in an associated increase in chronic disease and disability, the challenge of managing the demand for hospital services will become even more arduous in the coming decades.

Although rehabilitation is an important component of the hospital system, there has been relatively little study of the barriers for acute hospital patients waiting for an inpatient rehabilitation bed, ${ }^{8-10}$ or the occurrence and causes of discharge barriers for patients remaining in hospital after they are deemed to no longer require inpatient rehabilitation for management of the activity limitations resulting from their impairment. ${ }^{10,11}$ I have previously reported findings from a survey of rehabilitation physicians in Australia in which $87 \%$ reported that barriers to discharge were an extreme, severe or moderate problem. ${ }^{10}$ In a prospective study of patients in two general rehabilitation wards I found that $16.4 \%$ of patients had a discharge barrier, which accounted for $21.0 \%$ of bed-days over the study period. ${ }^{11}$ A few studies have also highlighted that admission and discharge barriers are a problem affecting patients with spinal cord damage (SCD) $)^{12-15}$ but none of these studies have classified the causes or quantified the impact of discharge barriers on patients with SCD.

The objectives of this study were to measure the proportion of patients admitted to a spinal rehabilitation unit (SRU) who developed a discharge barrier, the cause(s) and duration of any discharge barrier, and to determine whether any demographic or clinical variables predicted the occurrence of a discharge barrier or the number of additional days in hospital. These outcomes will help identify opportunities for improvement in the length of stay (LOS) for patients with SCD. The hypothesis is that patients with discharge barriers will have a longer LOS in SRU.

\section{METHODS}

\section{Setting}

The SRU at Caulfield Hospital, Victoria, Australia is a 12-bed adult inpatient unit. It is located in a public hospital and funded by the State. Patients are referred from both private and public hospitals, mainly from greater metropolitan Melbourne, but also from elsewhere in the State. Many patients are admitted from the acute care tertiary hospital in the inner-south of metropolitan Melbourne that is part of the same hospital network as the SRU. Because the other major SRU in Melbourne focuses on patients with traumatic spinal cord injury (SCI) and does not routinely admit patients with non-traumatic spinal cord myelopathy (SCM). The SRU at Caulfield hospital admits mainly patients with SCM, however, our SRU has no specific bias in its' admission criteria towards or against any particular aetiology of SCD.

${ }^{1}$ Spinal Rehabilitation Service, Caulfield Hospital, Alfred Health, Melbourne, Victoria, Australia and ${ }^{2}$ Epworth-Monash Rehabilitation Medicine Unit, Monash University, Melbourne, Victoria, Australia

Correspondence: Dr P New, Spinal Rehabilitation Service, Caulfield Hospital, Alfred Health, 260 Kooyong Road, Caulfield, Victoria 3162, Australia

E-mail: p.new@cgmc.org.au

Received 7 April 2014; revised 20 August 2014; accepted 27 August 2014; published online 30 September 2014 


\section{Study design and participants}

This was a prospective open cohort case series of consecutive patients with SCD admitted into the SRU between 1st January 2008 and 31st July 2013. Patients in the SRU after the 31st July 2013 were monitored until discharge to determine their outcome. All patients with a recent onset of SCD admitted into the SRU were included in the study. Patients with chronic SCD readmitted to hospital for management of late-onset complications after a previous rehabilitation admission were excluded.

Many of the participants in this study were also included in a recent paper $(n=347)$ that reported on the process barriers from acute hospital admission until transfer to the SRU ( $n=283)$, admission into other rehabilitation units, or alternative destinations. ${ }^{15}$ This present project started about 15 months after the study that focussed on the acute hospital process barriers so it does not include all participants from the previous study.

\section{Outcome measures}

The main outcome variables were the occurrence of a discharge barrier, the cause(s) and the duration of the additional unnecessary days in hospital arising as a result of the discharge barrier (from onset until resolution). When multiple discharge barriers occurred simultaneously any overlapping days were not double-counted when performing the regression analysis and reporting the total unnecessary days in hospital.
The definition of a discharge barrier and the classification of causes were based on recently validated work in developing these for rehabilitation patients ${ }^{16}$ and include the following categories: family negotiations; occupational therapy home assessment; home modifications; equipment necessary for discharge; carer funding; carer recruiting and training; alternative accommodation (when a patient is not able to return to their previous residence and without any readily available alternative); long-term and supported care or services and equipment assessment/approval; residential care (for example, waiting for nursing home or hostel care to be available); guardian/power of attorney appointment; competency assessment; waiting specialist review; or ambulatory rehabilitation availability, as shown in Table 1.

The need for ongoing inpatient rehabilitation and the occurrence and causes of a discharge barrier were monitored in the weekly multidisciplinary team meeting. The determination that a patient had a discharge barrier and no longer needed admission in the SRU was made on the basis of the treating teams' expertise and the following definition of a discharge barrier, ${ }^{16}$ 'A discharge barrier is considered to occur when the treating team believe that there are no longer any goals of therapy or treatment that require inpatient rehabilitation and yet the patient is unable to be discharged.' In applying this definition the following are assumed: (1) the patients' activity limitations, body functions and structural dysfunction have been addressed to an adequate degree, including safety considerations, such that it is no longer necessary to continue rehabilitation in an inpatient setting; and (2) environmental barriers

Table 1 The causes and definitions of the different discharge barriers from SRU, the proportion of patients with each barrier and the associated additional unnecessary days in hospital

\begin{tabular}{|c|c|c|c|}
\hline Cause and definition of discharge barrier ${ }^{16}$ & $\begin{array}{l}\text { Patients } \\
\text { with discharge } \\
\text { barrier }(\%)^{\mathrm{a}}\end{array}$ & $\begin{array}{l}\text { Additional } \\
\text { unnecessary } \\
\text { days in SRU } \\
\qquad \%)^{\text {a }}\end{array}$ & $\begin{array}{l}\text { Median (IQR) } \\
\text { additional } \\
\text { unnecessary } \\
\text { days in SRU }\end{array}$ \\
\hline $\begin{array}{l}\text { Long-term and supported care or services and equipment assessment/approval: patient referred to a service or } \\
\text { organisation for confirmation of appropriateness and necessity of supported care (nursing home or hostel) or } \\
\text { long-term services or equipment. Includes waiting for the assessment; determination of level of care or range } \\
\text { of services and equipment; related paperwork; and where relevant, confirmation that no option available for } \\
\text { alternative care, where this process is required. }\end{array}$ & $37(41.9)$ & $606(19.1)$ & $11(7-15)$ \\
\hline $\begin{array}{l}\text { Residential care: waiting for high level (nursing home) or low level (hostel or supported residential service) } \\
\text { residential care accommodation to be available. }\end{array}$ & $36(41.9)$ & 697 (21.9) & $15(9.5-26)$ \\
\hline $\begin{array}{l}\text { Home modifications: patient waiting home modifications that are essential to ensure safe access and care at } \\
\text { home after discharge. Includes funding and completion of modifications. }\end{array}$ & $26(30.2)$ & $902(28.4)$ & $20.5(11-41)$ \\
\hline $\begin{array}{l}\text { Equipment: delay waiting for necessary equipment to be available, after specific equipment needs have been } \\
\text { identified and prescribed that are essential to ensure safe care after discharge. Includes funding and supply of } \\
\text { equipment. }\end{array}$ & $15(17.4)$ & $691(21.8)$ & $37(13-63)$ \\
\hline Carer recruiting and training: waiting for recruiting and training of carers to ensure safe care after discharge. & $8(9.3)$ & $430(13.5)$ & $38(16-55.5)$ \\
\hline Accommodation: patient has no available suitable accommodation options. & $7(8.1)$ & $540(17.0)$ & $35(17-50)$ \\
\hline Carer funding: patient waiting funding for carers to ensure safe care after discharge. & $3(3.5)$ & $81(2.6)$ & $27(5-49)$ \\
\hline $\begin{array}{l}\text { Ambulatory rehabilitation: patient waiting assessment and/or availability of ambulatory rehabilitation services } \\
\text { and no longer needing intensity of inpatient rehabilitation but the team feels patient is not able to be } \\
\text { discharged until ambulatory rehabilitation is confirmed and available. }\end{array}$ & $3(3.5)$ & $58(1.8)$ & $28(1-29)$ \\
\hline $\begin{array}{l}\text { Guardian/power of attorney appointment: application made for determining power of attorney or guardian for } \\
\text { making a decision that is blocking discharge planning and patient not competent and no nominated person } \\
\text { existing. Also includes subsequent delay in decisions being made by nominated guardian regarding discharge } \\
\text { planning. }\end{array}$ & $3(3.5)$ & $77(2.4)$ & 27 (22-28) \\
\hline $\begin{array}{l}\text { Occupational therapy home assessment: patient no longer needs inpatient rehabilitation but home visit not yet } \\
\text { done (but believed to be required) to confirm safe access and internal environment. }\end{array}$ & $1(1.1)$ & $1(0.0)$ & 1 \\
\hline
\end{tabular}

Abbreviations: IQR, interquartile range; SRU, spinal rehabilitation unit.

alncludes patients with multiple barriers so percentage totals greater than $100 \%$.

'In this sample all the 'other' barriers were patients waiting for transfer to a rehabilitation unit in a regional centre closer to the patients' home. 
and facilitators for discharge have been optimised within the limit of readily available resources. This definition allowed the team to consider a barrier to exist when resources or services (for example, carers, funding for equipment or home modifications or ambulatory rehabilitation) are not readily available to enable discharge to proceed but the patient no longer needed inpatient care.

The following information was also recorded: referral source (same health network or another network); age on admission to acute hospital (years); gender; level of SCD (tetraplegia or paraplegia) and aetiology of SCD (traumatic SCI or non-traumatic SCM). At SRU admission and discharge the American Spinal Injury Association Impairment Scale (AIS) grade of injury ${ }^{17}$ and the motor subscale of the Functional Independence Measure (FIM) was recorded. ${ }^{18}$

Patients transferred back to an acute hospital for elective or emergency treatment during the course of their rehabilitation and who were subsequently readmitted back into the SRU were considered as having a continuation of their initial admission and not a separate new admission.

\section{Data collection and storage}

The occurrence of a discharge barrier, the cause(s) and date of onset or resolution were noted during the twice-weekly ward rounds and confirmed during the weekly team meeting. The data were recorded in a passwordprotected database prospectively by the advanced trainee in rehabilitation medicine or the unit head and reviewed by the unit head weekly to confirm their accuracy.

\section{Statistical analysis}

Descriptive analysis was performed including proportions, medians and interquartile range. The relationship between the occurrence of a discharge barrier and categorical variables was calculated using the Chi-squared test. The Wilcoxon rank-sum (Mann-Whitney) test was used to calculate the difference in the population distribution between variables that were not normally distributed. Odds ratios for the occurrence of a discharge barrier were calculated for the different comparison groups (males vs females, paraplegia vs tetraplegia, AIS grade A, B or C vs AIS D and SCI vs SCM).

The influence of the patients' age, gender, level of injury, AIS grade (dichotomised as AIS grade A, B or C vs AID D), aetiology (SCI vs SCM) and the discharge FIM-motor subscale on (a) the occurrence of a discharge barrier and (b) total number of unnecessary days in hospital, were assessed using multivariable logistic and linear regressions (backwards inclusion), respectively. The duration of unnecessary hospitalisation was log-transformed to facilitate parametric analysis. Age was categorised into three groups
$(<50,50-64$ and $\geqslant 65$ years) corresponding to different aged-based criteria for accessing programs or services available to patients at discharge.

All applicable institutional and governmental regulations concerning the ethical use of human volunteers were followed during the course of this research. The Alfred Health Human Research Ethics Committee approved the project. $P$ values of less than 0.05 were deemed statistically significant. Stata 12 for Windows (StataCorp, College Station, TX, USA) was used for statistical analysis.

\section{RESULTS}

There were 263 patients admitted during the study period but 28 were excluded (elective admissions from community), leaving 235 patients in the analysis, ranging in age from 17 to 88 years. On admission, 51 $(21.7 \%)$ patients were AIS grade A, $25(10.6 \%)$ were AIS B, 79 (33.6\%) AIS C and $80(34.0 \%)$ were AIS D.

Overall, 86 patients $(36.6 \%$, 95\% confidence interval $30.4-43.1 \%)$ patients had a discharge barrier. The reasons for a discharge barrier and their definition, ${ }^{16}$ the proportion of patients with each barrier and the number of associated additional unnecessary days in hospital is shown in Table 1. No patient had a discharge barrier due to waiting for competency assessment or a specialist review. The most common causes of a discharge barrier were: waiting for approval for long-term and supported care or services, residential care, home modifications, family deliberations regarding discharge planning and the provision of equipment necessary for discharge. The reasons accounting for the greatest number of additional hospital days were: home modifications, residential care, equipment necessary for discharge, waiting for approval for long-term and supported care or services and waiting for accommodation for people unable to return to their previous residence without readily available alternatives. Among patients with a discharge barrier, 34 had one barrier, 37 had two barriers and 15 patients had three or more barriers to discharge.

The proportion of patients in different categories (gender, level of injury, AIS grade on discharge and aetiology), their age, LOS in the SRU, motor FIM on admission and discharge and the proportion with a discharge barrier are shown in Table 2. Most patients $(n=162$, $68.9 \%)$ were discharged home, $35(14.9 \%)$ were transferred to a nursing home, $16(6.8 \%)$ were transferred to another rehabilitation

Table 2 Key patient groups and their disability on admission and discharge, the proportion with a discharge barrier, length of stay and duration of unnecessary additional days in hospital

\begin{tabular}{|c|c|c|c|c|c|c|c|c|}
\hline & n (\%) & $\begin{array}{l}\text { Age median } \\
(I Q R)^{\mathrm{a}}\end{array}$ & $\begin{array}{c}\text { FIM-motor } \\
\text { admission } \\
\text { median }(I Q R)^{\mathrm{b}}\end{array}$ & $\begin{array}{c}\text { FIM-motor } \\
\text { discharge } \\
\text { median }(I Q R)^{\mathrm{c}}\end{array}$ & $\begin{array}{l}\text { Patients with } \\
\text { a discharge } \\
\text { barrier } \mathrm{n}(\%)^{\mathrm{d}}\end{array}$ & $\begin{array}{c}\text { Odds Ratio of } \\
\text { discharge barrier } \\
(95 \% \mathrm{Cl})\end{array}$ & $\begin{array}{l}\text { LOS median } \\
\text { (IQR }^{f}\end{array}$ & $\begin{array}{c}\text { Additional unnecessary } \\
\text { days in hospital } \\
\text { median (IQR)g }\end{array}$ \\
\hline Males & $138(58.7)$ & $61(48-72)$ & $32(20-45)$ & $73(47-82)$ & $47(34.1)$ & 1 & $60.5(29-111)$ & $27(15-41)$ \\
\hline Females & 97 (41.3) & $65(52-74)$ & $29(23-35)$ & $63(36-77)$ & $39(40.2)$ & $1.3(0.8-2.2)$ & 70 (42-107) & $26(7-49)$ \\
\hline Paraplegia & $177(75.3)$ & $63(48-73)$ & $31(24-43)$ & $70(43-80)$ & $60(33.9)$ & 1 & $59(34-102)$ & $25.5(9.5-45.5)$ \\
\hline Tetraplegia & $58(24.7)$ & $62(52-72)$ & $24(13-37)$ & $71(32-81)$ & $26(44.8)$ & $1.6(0.9-2.9)$ & $88.5(47-120)$ & $30.5(22-41)$ \\
\hline AIS A, B, C & $100(42.5)$ & $63(51-75)$ & $25(19-31)$ & $40.5(25.5-65)$ & $45(45)$ & 1 & $81.5(46.5-132)$ & $26(11-46)$ \\
\hline AIS D & $135(57.5)$ & 62 (47-73) & 35 (28-49) & 77 (68-83) & $41(30.4)$ & $0.5(0.3-0.9)$ & 55 (28-97) & $29(14-42)$ \\
\hline $\mathrm{SCl}$ & $48(20.4)$ & $58.5(39.5-72)$ & $28(14-41.5)$ & $74.5(52-83)$ & $17(35.4)$ & 1 & $72.5(28-111.5)$ & $28(26-35)$ \\
\hline SCM & $187(79.6)$ & $64(51-73)$ & $30(23-42)$ & 69 (40-79) & 69 (36.9) & $0.9(0.5-1.8)$ & 64 (36-108) & $26(11-45)$ \\
\hline Total & 235 & $63(49-73)$ & $30(22-42)$ & $71(40-80)$ & $86(36.6)$ & - & $64(34-111)$ & $27(11-45)$ \\
\hline
\end{tabular}

Abbreviations: AIS, American Spinal Injury Association (ASIA) Impairment Scale; FIM-motor, functional independence measure motor subscale; IQR, interquartile range; LOS, length of stay;

$\mathrm{SCl}$, spinal cord injury; SCM, spinal cord myelopathy; $95 \% \mathrm{Cl}, 95 \%$ confidence interval.

${ }^{\text {aAge: }}$ gender $Z=-1.9, P=0.06$; level $Z=0.05, P=1.0$; AIS $Z=0.8, P=0.4$; aetiology $Z=1.6, P=0.1$

${ }^{b}$ FIM-motor admission: gender $Z=1.1, P=0.3$; level $Z=3.4, P=0.0006$; AIS $Z=-5.9, P<0.0001$; aetiology $Z=1.5, P=0.1$.

CFIM-motor discharge: gender $Z=2.3, P=0.02$; level $Z=0.05, P=1.0$; AIS $Z=8.9, P<0.0001$; aetiology $Z=1.7, P=0.08$.

dPatients with discharge barrier: gender $\chi^{2}=1.4, P=0.2$; level $\chi^{2}=1.8, P=0.2$; AIS $\chi^{2}=4.4, P=0.04$; aetiology $\chi^{2}=0.04, P=0.8$

eGender $\chi^{2}=0.9, P=0.3$; level $\chi^{2}=2.2, P=0.1$; AIS $\chi^{2}=5.3, P=0.02$; aetiology $\chi^{2}=0.04, P=0.8$.

${ }^{f} \mathrm{LOS}$ in SRU: gender $Z=1.1, P=0.3$; level $Z=-2.3, P=0.02$; AIS $Z=3.4, P=0.0007$; aetiology $Z=-0.04, P=1.0$

gAdditional unnecessary days in hospital: gender $Z=0.5, P=0.6$; level $X=-1.2, P=0.2$; AIS $Z=0.04, P=1.0$; aetiology $Z=-0.4, P=0.7$. 
Table 3 Multivariable logistic regression for the occurrence of a discharge barrier

\begin{tabular}{lcc}
\hline Variable & Odds ratio $(95 \% \mathrm{Cl})$ & Z, P \\
\hline $\begin{array}{l}\text { Age group } \\
\quad 64\end{array}$ & $1^{\mathrm{a}}$ & - \\
$\quad 265$ & $2.2(1.2-4.0)$ & $2.6,0.01$ \\
Discharge motor FIM & $0.97(0.96-0.99)$ & $-3.6,0.001$ \\
\hline
\end{tabular}

Abbreviations: $95 \% \mathrm{Cl}$, 95\% confidence interval; FIM, functional independence measure. aReference group.

unit in a regional centre closer to their home for ongoing rehabilitation and $22(9.4 \%)$ went to other destinations (acute hospitalization and did not return, $n=17$; retirement to village, $n=1$; hostel, $n=2$; palliative care, $n=1$; other, $n=1)$. Patients discharged to a nursing home had much higher odds of a discharge barrier (odds 16.6, 95\%CI 5.3-52.2, $\left.\chi^{2}=43, P<0.0001\right)$ compared with patients who went to other destinations.

Over the study period $17.5 \%$ (3176/18 184) of all bed-days were occupied by patients who were deemed to be clinically ready for discharge from the SRU but who had a discharge barrier. Thirty-five patients $(40.7 \%)$ with a discharge barrier spent more than one additional month in rehabilitation and five patients had greater than 100 additional unnecessary days of hospitalisation (maximum 357 days). The LOS (median 107 days, IQR 74-149) for patients with a discharge barrier was significantly $(Z=-7.9, P<0.0001)$ greater than that for patients who did not have a discharge barrier (median LOS 48 days, IQR 26-77).

Regression analysis showed that older patients ( $\geqslant 65$ years) had significantly greater odds of a discharge barrier than the younger group and the odds were reduced significantly with lesser disability on discharge (Table 3 ). The discharge FIM-motor subscale was the only variable that was significant $(P=0.004)$ in the linear regression assessing the variables predicting the number of additional days in hospital but this explained only $9 \%$ of the variance in additional unnecessary bed-days.

\section{DISCUSSION}

Barriers to discharge from the SRU were relatively common and the number of unnecessary bed-days 'blocked' by these patients was substantial. These unnecessary days in hospital represent a substantial waste of health-care resources. Our hypothesis was proved-patients with a barrier to discharge have a significantly longer LOS.

Older patients had increased odds of a discharge barrier, in contrast to a previous study. ${ }^{11}$ This might reflect the difficulty in sometimes predicting neurological and functional recovery in patients with SCM that formed the majority of patients due to the incomplete nature of their SCD and who typically were older. Family deliberations regarding discharge decisions (home with family providing care themselves or paying for cares vs residential care) were certainly a factor in numerous cases.

Barriers to the discharge of patients with SCD from a SRU can result in a number of adverse consequences. There is a flow-on affect that reduces access for other patients with SCD in acute hospital waiting for a SRU bed. ${ }^{15}$ As well as wasting limited health-care resources that could be better utilized, when patients are in hospital for longer than necessary each additional day of hospitalisation is reported to increase by $6 \%$ the risk of iatrogenic complications, such as medication errors, nosocomial infections and falls. ${ }^{19}$
Our findings are consistent with previous studies regarding the causes of barriers to discharge for people with SCD. A study from The Netherlands highlighted problems for patients with SCD waiting for home modifications or alternative accommodation-a third of patients had their discharge delayed by a median of 15 weeks. ${ }^{20} \mathrm{~A}$ study from the USA on barriers to community integration for patients with SCI found that the most common barriers were equipment issues and lack of environmental and home assistance. ${ }^{21}$ Our findings provide substantiation of the survey results of perceptions from SRUs in 10 countries regarding problems with admission and discharge barriers, which found that the most common barriers matched those identified in this project. ${ }^{14}$

In a study of barriers to discharge from two rehabilitation units in a separate network to the SRU elsewhere in Melbourne, Australia, I found that $16.4 \%$ of patients had a barrier to discharge that accounted for $21.0 \%$ of all bed-days. ${ }^{11}$ In this present study the proportion of patients with a discharge barrier was almost double but the proportion of bed-days occupied unnecessarily was slightly less. The reasons for a discharge barrier accounting for the greatest number of bed-days in hospital unnecessarily in the previous study were patients' non-weight bearing after lower limb fractures, home modifications, carer funding, family negotiations, accommodation and equipment necessary for discharge. Besides the non-weight bearing category, which is not relevant for patients with SCD in SRU, all the other barriers featured prominently in this study.

A strength of this study is the use of a validated classification for discharge barriers to identify opportunities for improvement. ${ }^{16}$ Although delays to discharge from SRUs for patients with SCD have been highlighted previously, ${ }^{14}$ these delays have not been systematically classified nor has the duration of the unnecessary days in hospital been quantified.

The results of this study cannot be generalised to other SRUs. This is because of the variability in hospital reimbursements systems and the organisation of care for patients with SCD that can influence length of stay. ${ }^{22}$ It is important to emphasise, however, that SRUs from many different countries have also reported problems with barriers to discharge. ${ }^{14}$ Furthermore, unless discharge barriers are measured, they cannot be improved. There is support internationally among those working in SRUs for prospective documentation of discharge barriers for benchmarking and quality improvement processes. ${ }^{14} \mathrm{~A}$ framework for planning strategies to address barriers to discharge has been presented previously. ${ }^{11}$

Limitations of this study are that data was collected from only one SRU. There was potentially subjectivity involved with identifying discharge barriers and their duration. This was mitigated by having senior team members reach consensus during the team meeting regarding the occurrence and duration of a barrier using the validated categories and definition of discharge barrier. ${ }^{16}$

In conclusion, further study of discharge barriers for patients in SRUs is necessary. Including different centres and an increased number of participants, with adequate power to explore predictors of discharge barriers and the interaction between barriers, would be ideal. Qualitative studies and process mapping of the patient journey would provide additional insights into exploring and addressing barriers to discharge for all patients, including those with SCD. Health care policy makers and managers should allocate greater resources to tackling patient-flow inefficiencies for patients with SCD. Although these patients are low volume compared with other impairments, they are responsible for considerable costs. ${ }^{23}$ Reducing discharge barriers for patients with SCD will potentially reduce iatrogenic complications and improve the efficiency of the hospital system. 


\section{DATA ARCHIVING}

There were no data to deposit.

\section{CONFLICT OF INTEREST}

The authors declare no conflict of interest.

\section{ACKNOWLEDGEMENTS}

The following Drs are thanked for their assistance with data collection: Irina Astrakhantseva, Puey Ling Chia, Seema Chopra, Harry Eeman, Kapil Gupta, Cristina Manu, Caroline McFarlane, Olivia Ong, Parinaz Sharifi, James Ting and especially Richard Bignell.

1 Trzeciak S, Rivers EP. Emergency department overcrowding in the United States: an emerging threat to patient safety and public health. Emerg Med J 2003; 20: 402-405.

2 Bernstein SL, Aronsky D, Duseja R, Epstein S, Handel D, Hwang U et al. The effect of emergency department crowding on clinically oriented outcomes. Acad Emerg Med 2009; 16: 1-10.

3 Eitel DR, Rudkin SE, Malvehy MA, Killeen JP, Pines JM. Improving service quality by understanding emergency department flow: a White Paper and Position Statement prepared for the American Academy of Emergency Medicine. J Emerg Med 2010; 38: 70-79.

4 Flintoft VF, Williams JI, Williams RC, Basinski AS, Blackstien-Hirsch P, Naylor CD. The need for acute, subacute and nonacute care at 105 general hospital sites in Ontario. Joint Policy and Planning Committee Non-Acute Hospitalization Project Working Group. CMAJ 1998; 158: 1289-1296.

5 Weaver FM, Guihan M, Hynes DM, Byck G, Conrad KJ, Demakis JG. Prevalence of subacute patients in acute care: results of a study of VA hospitals. J Med Syst 1998; 22: 161-172.

6 Carey MR, Sheth H, Braithwaite RS. A prospective study of reasons for prolonged hospitalizations on a general medical teaching service. J Gen Intern Med 2005; 20 $108-115$.

7 United Nations (ed.). Report of the Second World Assembly on Ageing; Madrid; 8-12 April 2002. United Nations: New York, NY, USA, 2002.

8 Bradley LJ, Kirker SG, Corteen E, Seeley HM, Pickard JD, Hutchinson PJ. Inappropriate acute neurosurgical bed occupancy and short falls in rehabilitation: implications for the National Service Framework. Br J Neurosurg 2006; 20: 36-39.
9 New PW, Poulos CJ. Functional improvement of the Australian health care system-can rehabilitation assist? Med J Aust 2008; 189: 340-343.

10 New PW, Cameron PA, Olver JH, Stoelwinder JU. Key stakeholders' perception of barriers to admission and discharge from inpatient subacute care in Australia. Med J Aust 2011; 195: 538-541.

11 New PW, Jolley DJ, Cameron PA, Olver JH, Stoelwinder JU. A prospective multicentre study of barriers to discharge from inpatient rehabilitation. Med J Aust 2013; 198: 104-108.

12 Pagliacci MC, Celani MG, Spizzichino L, Zampolini M, Aito S, Citterio A et al. Spinal cord lesion management in Italy: a 2-year survey. Spinal Cord 2003; 41: 620-628.

13 Amin A, Bernard J, Najarajah R, Davies N, Gow F, Tucker S. Spinal injuries admitted to a specialist centre over a 5-year period: a study to evaluate delayed admission. Spinal Cord 2005; 43: 434-437.

14 New PW, Scivoletto G, Smith É, Townson A, Gupta A, Reeves RK et al. International survey of perceived barriers to admission and discharge from spinal cord injury rehabilitation units. Spinal Cord 2013; 51: 893-897.

15 New PW. Reducing the process barriers in acute hospital for patients with spinal cord damage patients needing spinal rehabilitation unit admission. Spinal Cord 2014; 52 472-476.

16 New PW, Cameron PA, Olver JH, Stoelwinder JU. Defining barriers to discharge from inpatient rehabilitation, classifying their causes, and proposed performance indicators for rehabilitation patient flow. Arch Phys Med Rehabil 2013; 94 201-208.

17 Kirshblum SC, Burns SB, Biering-Sorensen F, Donovan W, Graves DE, Jha A et al International standards for neurological classification of spinal cord injury (Revised 2011). J Spinal Cord Med 2011; 34: 535-546.

18 Guide for the Uniform Data Set for Medical Rehabilitation (including the FIM instrument), version 5.1. State University of New York at Buffalo: Buffalo, NY, USA. 1997.

19 Andrews LB, Stocking C, Krizek L, Gottlieb L, Krizek C, Vargish T et al. An alternative strategy for studying adverse events in medical care. Lancet 1997; 349: 309-313.

20 Post MWM, van Asbeck FWA, van Dijk AJ, Schrijvers AJP. Services for spinal cord injured: availability and satisfaction. Spinal Cord 1997; 35: 109-115.

21 Silver J, Ljungberg I, Libin A, Groah S. Barriers for individuals with spinal cord injury returning to the community: a preliminary classification. Disabil Health J 2012; 5 190-196.

22 New PW, Townson A, Scivoletto G, Post MWM, Eriks-Hoogland I, Gupta A et al. International comparison of the organisation of rehabilitation services and systems of care for patients with spinal cord injury. Spinal Cord 2013; 51: 33-39.

23 New PW, Jackson T. The costs and adverse events associated with hospitalization of patients with spinal cord injury in Victoria, Australia. Spine 2010; 35: 796-802. 